\title{
O CUSTO DO ENCARCERAMENTO NO BRASIL SOB A ÓTICA DA ANÁLISE ECONÔMICA DO DIREITO
}

\author{
Carlos Lélio Lauria Ferreira ${ }^{137}$ \\ Nestor Eduardo Araruna Santiago ${ }^{138}$
}

Recebido em: 20/08/2018

Aprovado em: 07/11/2018

\begin{abstract}
RESUMO
O presente artigo elabora levantamento do custo do encarceramento no Brasil sob a ótica da Análise Econômica do Direito. Justifica-se a escolha do tema por se tratar de questão desconsiderada no mundo jurídico-penal e penitenciário brasileiro, e também pouco explorada no meio acadêmico e tratada de forma equivocada e exagerada nos meios de comunicação de massa. O objetivo da pesquisa é mostrar que a análise econômica do Direito é instrumento fundamental para determinar o custo do encarceramento em suas diferentes vertentes. Constatou-se que o cálculo do custo da privação da liberdade no Brasil incorre na omissão de aspectos relevantes que comprometem a veracidade das informações utilizadas, invariavelmente, em propostas de políticas públicas na área da segurança. Para demonstrar essa discrepância, comparam-se dados colhidos em fontes variadas, com ênfase a informações colhidas em instituições oficiais e análise crítica da realização da justiça por meio do encarceramento.
\end{abstract}

Palavras-chave: Encarceramento. Custo. Análise Econômica do Direito. Eficiência.

\section{INTRODUÇÃO}

Este artigo apresenta exame crítico e circunstanciado sobre o custo do encarceramento no Brasil sob a ótica da Análise Econômica do Direito, por meio da interdisciplinaridade e de

\footnotetext{
${ }^{137}$ Doutorando em Direito Constitucional pelo Centro Universitário de Ensino Superior do Amazonas - CIESA - e pela Universidade de Fortaleza. Especialista em Direito Público pela Fundação Getúlio Vargas e especialista em Direito Penal e Processual Penal pela Universidade Cândido Mendes. Professor da Escola da Magistratura do Amazonas e do CIESA. Procurador de Justiça do Ministério Público do Estado do Amazonas.

${ }^{138}$ Doutor em Direito Tributário, com estágio Pós-Doutoral em Direito pela Universidade do Minho - Portugal. Mestre e Especialista em Ciências Penais pela Universidade Federal de Minas Gerais - UFMG. Professor Titular do Programa de Pós-Graduação Stricto Sensu em Direito Constitucional e do Curso de Graduação em Direito da Universidade de Fortaleza - UNIFOR. Professor Adjunto IV do Curso de Graduação em Direito da Universidade Federal do Ceará - UFC. Advogado Criminalista.
} 
métodos de investigação sobre o aspecto conceitual e contábil dos custos enquanto instrumento de precificação de uma atividade.

Pretende-se construir análise do dispêndio com a política de aprisionamento no Brasil, considerando válidas para a consecução desse fim as terminologias Law and Economics e Economic Analysis of Law, rigor também posto de lado em relação aos termos custo, preço, gasto, desembolso e despesa, tratados neste trabalho com a mesma significação.

Sob a ótica da Análise Econômica do Direito, reflete-se sobre a eficiência e o custobenefício do encarceramento no Brasil. Pela natureza do sistema penitenciário, o encarceramento não pode ter custos díspares e exorbitantes. O custo do encarceramento deve refletir a preocupação com administração penitenciária eficiente, sobretudo quanto à fase final do sistema de justiça criminal em que se verifica sua eficácia: a execução da pena. Em síntese, busca-se dar ao tema os contornos necessários para que não fuja da linha de pesquisa deste artigo.

Para comprovação temática, partiu-se da análise da composição do custo do encarceramento, a qual se revelou causa rudimentar da execução atabalhoada de políticas públicas na área criminal, o que ocasiona tomada de decisões "no escuro" pela ausência de dados confiáveis e impacto sério na economia do país. É por isso importante distinguir custo do crime e custo do encarceramento, essencial para compreender a proposta deste artigo.

Busca-se também mostrar as proposições para reduzir as despesas do Estado a fim de manter pessoas longe do convívio social, chamadas de "medidas de desencarceramento"; dessa perspectiva faz-se um paralelo com o entendimento doutrinário sobre o custo dos direitos.

Aborda-se a questão do menor custo e maior eficiência nos presídios públicos e terceirizados, com referência à percepção do Ministério Público do Estado do Amazonas, ao propor seis ações civis públicas autônomas, com foco relacionado à defesa dos direitos dos presos, após massacres ocorridos nos presídios do Estado em janeiro de 2017.

O último tópico faz análise circunstanciada do princípio da eficiência e sua inclusão no ordenamento jurídico brasileiro, seu tratamento diante dos demais princípios da Administração Pública e sua concepção a partir da Análise Econômica do Direito.

\section{ASPECTO CONCEITUAL E EVOLUÇÃo Histórica dA ANÁliSE ECONÔMICA DO DIREITO}


O pilar fundamental do tema aqui dissertado consiste em propor hipóteses de aplicação da Análise Econômica do Direito ${ }^{139}$ como instrumento de avaliação do custo do encarceramento no Brasil, a partir do pressuposto de que o estudo do Direito e da Economia permite a análise das questões jurídicas sob a perspectiva do problema econômico, o que se traduz em exercício de interdisciplinaridade.

Sabe-se que a relação entre Direito e Economia, e sua abordagem de modo interdisciplinar, tem origem na antiguidade. Na tradição anglo-saxônica, segundo Marcia Ribeiro, apesar do uso indistinto em alguns casos das duas expressões, Economic Analysis of Law foi cunhada por Posner (1986) e se liga aos seguidores das hipóteses teóricas adotadas por esse autor; já a expressão Law and Economic é mais antiga e abarca diversas correntes teóricas, sendo Economic Analysis of Law apenas uma delas. No Brasil, os estudos do atual movimento da Law and Economic têm sido referidos como Análise Econômica do Direito, sendo que a expressão Direito e Economia não parece gozar de grande aceitação. É inegável que Law and Economics desempenha relevante papel na apuração dos custos de qualquer atividade, reconhece Ferreira (2015), tal qual ocorre com o encarceramento de criminosos.

A Análise Econômica do Direito tenta explicar o comportamento dos indivíduos perante regras e efeitos destas na consecução de resultados eficientes, segundo Alejandro Alvarez ${ }^{140}$. O autor ressalta, em harmonia com Spector (2003), que a Análise Econômica do Direito: (i) proporciona um modelo analítico unificado para explicar uma formação de normas jurídicas que parecem não ter conexão entre si; (ii) é premissa fundamental do modelo: que indivíduos são agentes racionais que escolhem ações para maximizar utilidades individuais com base em uma ordem coerente de preferências transitivas; (iii) assume que existe uma noção básica de eficiência consistente e inteligível para avaliar as instituições jurídicas.

Faz coro a esse entendimento a lição de Mackaay \& Rousseau (2015) ao lembrar que a Análise Econômica do Direito, usando conceitos da ciência econômica, atualiza racionalidade subjacente das normas jurídicas e os principais efeitos previsíveis de suas mudanças, ferramenta preciosa para o legislador, para o juiz e para a doutrina convidada a exercer a

\footnotetext{
${ }^{139}$ A Análise Econômica do Direito implica o uso das ferramentas próprias da Economia às normas jurídicas, reinterpretando o ordenamento jurídico. Exemplo: Recurso Especial 962.934/MS, de relatoria do ministro Herman Benjamin. O caso trata da responsabilidade civil do Estado pelas más condições dos presídios, em que um presidiário pleiteou indenização moral individual em razão da superlotação e da falta de condições mínimas nas celas. $\mathrm{O}$ entendimento ficou superado porque em fevereiro do ano de 2017 o Supremo Tribunal Federal aprovou a tese para fim de repercussão geral de ser cabível indenizar o presidiário pelas más condições do sistema carcerário. Disponível em: 〈http://www.conjur.com.br/2017-jul-10/opiniao-analise-economica-direito-meio-justica-social> Acesso em: 5 dez. 2017.

140 Análise Econômica do Direito: contribuições e desmistificações. Disponível em: <http://direitoestadosociedade.jur.puc-rio.br/media/Bugallo_n29.pdf> Acesso em: 4 dez. 2017.
} 
nobre missão de trazer à luz os fundamentos do direito e mostrar os caminhos para sua adaptação a novas realidades, o que também é a impressão de Friedman (2000), no sentido de que a Análise Econômica do Direito propõe leitura das regras jurídicas que as avalie por seus efeitos de estímulo e mudanças de comportamento das pessoas em resposta aos mesmos.

$\mathrm{Na}$ abordagem do artigo "Direito e Economia", Rachel Sztajn lembra que os economistas dizem que as demandas são ilimitadas, mas os meios (recursos) para atender a elas são finitos, escassos. Em face disso (impossibilidade de atender a todas as demandas), alocam-se os bens de forma racional, maximizando o resultado do uso, reduzindo perdas e desperdícios. Considerando os bens (ou meios) escassos, perseguir o uso eficiente interessa a todos, também ao Direito ${ }^{141}$.

\section{COMPOSIÇÃO DO CUSTO DO ENCARCERAMENTO NO BRASIL: CONSTITUIÇÃO TERATOLÓGICA}

Presente em todos os atos da vida quotidiana, a noção sobre custos é permeada por deturpação, incitando uso inadequado nas práticas contábil e administrativa. $\mathrm{O}$ vocábulo 'perda', na contabilidade, equivale a 'custo' e, como conceitua Dutra (2010), um 'gasto' de forma involuntária e anormal, conceito apropriado no caso do encarceramento no Brasil que tem política de aprisionamento sem qualquer retorno para a sociedade, cujos seres humanos, ao ser privados da liberdade, tornam-se piores e mais custosos. Afigura-se também adequado o termo 'desperdício', entendido por Dubois (2009) como gasto por não ocorrer o aproveitamento normal de todos os seus recursos, que não é notado de maneira imediata e que somente com bons controles poderá ser diagnosticado.

Ao discorrer sobre a economia política da pena, Serra (2009) destaca a superlotação das penitenciárias brasileiras, o que expande o poder de grupos criminosos, ingrediente básico do aumento do custo do encarceramento. À parte, os impactos da política de encarceramento no Brasil extrapolam a figura da pessoa encarcerada. A maioria das pessoas, contribuintes ou não, paga a conta pelo alto preço do encarceramento. Como adverte Schmidtz (2009), esse fenômeno como externalidade negativa, chamado de 'custo colateral', parte do custo de uma ação que apresenta impacto sobre os espectadores.

141 Disponível em: <http://www.passeidireto.com/arquivo/24598215/direito--economia---decio-zylbersztajn-rachel-sztajn/5> Acesso em: 5 dez. 2017. Publicado na Revista de Direito Mercantil - 144. 
Encarcerar exige ponderação de suas consequências jurídicas, sociais e econômicas. Além dos custos diretos, despesas como segurança, alimentação, energia e saúde, há de se considerar os custos indiretos do aprisionamento, os custos sociais, os quais, de acordo com relatório do Banco Interamericano de Desenvolvimento ${ }^{142}$, advêm de manter uma população inativa (caso não desenvolva atividades produtivas nos presídios), bem como os custos do bem-estar das famílias dos presidiários e as consequências para o mercado de trabalho quando os presidiários deixam o sistema carcerário.

O cálculo do custo de um presídio é feito da seguinte forma: divide-se o número de encarcerados em cada mês de regime fechado, semiaberto e aberto, submetidos à medida de segurança e presos provisórios pelas despesas administrativas (despesas com pessoal como salário e gestão penitenciária), entre outras despesas (aluguel, alimentação, recursos de higiene pessoal, etc.). Assim, tem-se o custo mensal do preso, ou seja, a população carcerária dividida pelas despesas administrativas do mês de referência ${ }^{143}$. Utiliza-se como fórmula de pagamento de um presídio submetido à administração terceirizada a seguinte equação: $\mathrm{PM}=$ $\mathrm{HF}+\mathrm{HV}-\mathrm{D}$, onde: $\mathrm{PM}=$ Pagamento mensal; $\mathrm{HF}=$ Honorário fixo por vaga; $\mathrm{HV}=$ Honorário variável por preso; $\mathrm{D}=$ Deduções.

Não há de se confundir o custo do crime com o custo do encarceramento, apesar de estar relacionados. Estudo do Banco Interamericano de Desenvolvimento (BID) mostra que o custo do crime e da violência no Brasil alcançou US\$ 91,38 bilhões em 2014 (cerca de $\mathrm{R} \$ 258,3$ bilhões), ou 3,78\% do PIB daquele ano, mais da metade (53\%) do custo total com crime e violência na América Latina e no Caribe - US\$171,78 bilhões, equivalente a 3,55\% do PIB da região - ou duas vezes mais que a média dos países desenvolvidos ${ }^{144}$.

O Anuário do Observatório de Mercados Ilícitos Transnacionais (OMI) da Federação das Indústrias do Estado de São Paulo, na edição de 2017, ao tratar dos impactos econômicos causados pela perda de faturamento em função de atividades criminosas, revela que a perda direta do setor industrial como vítima de crimes e violência tem efeito sobre o próprio desempenho econômico da empresa, que perde em "produtos, equipamento ou dinheiro", ou,

\footnotetext{
142 Os custos do crime e da violência: novas evidências e constatações na América Latina e Caribe. Laura Jaitman. Monografia do BID.

${ }^{143}$ Resolução n ${ }^{\circ}$ 6/2012-CNPCP

${ }^{144}$ Para calcular o valor, o banco utilizou uma metodologia contábil e outras duas adicionais, considerando custos diretos com segurança pública e privada e alguns indiretos, como o da renda de trabalho não gerada por detentos.

Disponível em: <http://oglobo.globo.com/economia> Acesso em: 4 dez. 2017.
} 
em segundo lugar, que necessita de altos gastos com segurança para se proteger dos riscos de vitimização $^{145}$.

\section{ENCARCERAMENTO E REALIZAÇÃO DA JUSTIÇA: ANÁLISE CRÍTICA}

Quando o crime é cometido, surge para o Estado o direito de aplicar o sistema de justiça criminal, que se completa com o cumprimento da pena. Há casos em que a comprovada má gestão do sistema de segurança atinge de forma perversa o orçamento familiar. A sociedade é obrigada a arcar com despesas excessivas para manter um criminoso afastado do meio social. A concepção de que a prisão cautelar e a decorrente da imposição de pena criminal asseguram o direito à tranquilidade e à paz social deve considerar que todos os direitos têm custos financeiros públicos, conforme atesta José Nabais ${ }^{146}$.

Sob tal ótica, discute-se o custo para financiar sistema que não consegue manter a pessoa encarcerada nem cumprir sua finalidade primordial: reinserção social. Tampouco se leva em consideração no cálculo do custo do encarceramento a fuga do preso provisório ou condenado. Pode-se argumentar que, com o preso foragido, o custo do presídio diminui. Dedução ilógica porque desconsidera a possibilidade de cometimento de novos crimes de custo inimaginável. Se a liberdade não tem preço, o encarceramento tem, e é alto. E a não concretização da justiça fica evidente quando se verifica outra discrepância nos dados oficiais: ficam de fora prejuízos de rebeliões, motins, mortes e gastos com transporte de presos para audiências e eventos extraordinários relacionados com o sistema penitenciário, o custo da apreensão de menores infratores e da superlotação prisional.

Tais componentes deitam à margem dos levantamentos sobre o custo do encarceramento no Brasil, citando-se como exemplo as despesas com transporte de presos. Estima-se que o gasto com a operação de deslocamento de presos que cumprem pena no sistema federal varia de $\mathrm{R} \$ 10 \mathrm{mil}$ a $\mathrm{R} \$ 22 \mathrm{mil}^{147}$. A escolta envolve estrutura da Força Aérea Brasileira (FAB) e das superintendências da Polícia Federal (PF) nos Estados. O custo de

\footnotetext{
${ }^{145}$ FIESP, Mercados ilícitos transnacionais em São Paulo: a economia criminal transnacional. São Paulo: FIESP, 2017.

146 A face oculta dos direitos fundamentais: os deveres e os custos dos direitos. Disponível em: <http://www.egov.ufsc.br/portal/sites/default/files/anexos/15184-15185-1-PB.pdf> Acesso em: 29 nov. 2017.

147 Informações do Departamento Penitenciário Nacional (DEPEN). Disponível em: <http://g1.globo.com/noticias/brasil/>. Acesso em: 7 dez. 2017.
} 
remoção de preso do sistema federal envolve valores como hora-voo, combustível de carros e de aeronaves, hora-extra e alimentação de policiais ${ }^{148}$.

Do mesmo modo, escapam do olhar os prejuízos causados por rebeliões em presídios, pagos pelo contribuinte. Em outras palavras, os valores usados para recuperar o estabelecimento penal são maiores que os recursos utilizados para prevenir o sinistro, sem considerar os danos pessoais, especialmente em caso de morte. Além disso, estima-se que há 189 mil adolescentes cumprindo medidas socioeducativas no país, a grande maioria em liberdade, o dobro do registrado um ano atrás (96 mil), conforme Cadastro Nacional de Adolescentes em Conflito com a Lei ${ }^{149}$.

Quanto à superlotação carcerária, estatísticas mostram que o total de pessoas encarceradas no Brasil chegou a 726.712 em junho de 2016. Em dezembro de 2014, era de 622.202. Houve crescimento de mais de 104 mil pessoas. Cerca de $40 \%$ são presos provisórios, ou seja, ainda não possuem condenação judicial ${ }^{150}$. O Brasil é o terceiro país com maior número de pessoas presas, atrás de Estados Unidos e China. O quarto país é a Rússia. A taxa de presos para cada 100 mil habitantes subiu para 352,6 indivíduos em junho de 2016. Em 2014, era de 306,22 pessoas presas para cada 100 mil habitantes ${ }^{151}$. A média nacional de custo por preso é de $\mathrm{R} \$ 2.400,00$, referente a sistema de segurança, contratação de agentes penitenciários e outros funcionários, alimentação e compra de vestuário, assistência médica e jurídica, entre outros, valor variável conforme a estrutura da unidade prisional, sua finalidade (para presos provisórios, definitivos, unidades masculinas ou femininas) e também de acordo com a região do país. Nas penitenciárias federais, administradas pelo Departamento Penitenciário Nacional (DEPEN), o governo gasta R $\$ 3.472,22$ por preso nas quatro unidades geridas $^{152}$.

O que constitui o nó górdio do sistema penitenciário não são as despesas com a administração prisional, mas os valores despendidos com a construção e reforma de estabelecimentos penais em todo o país. A vaga no sistema prisional é cara, ineficaz e representa um escárnio em nosso país com um dos maiores déficits habitacionais do mundo,

\footnotetext{
${ }^{148}$ Disponível em: <http://g1.globo.com/noticias/brasil/>. Acesso em: 7 dez. 2017.

${ }^{149}$ Disponível em: <http://g1.globo.com/politica/noticia/2016/11/>. Acesso em: 8 dez. 2017.

150 Mais da metade dessa população é de jovens de 18 a 29 anos e 64\% são negros. Os dados são do Levantamento Nacional de Informações Penitenciárias (INFOPEN) órgão do Departamento Penitenciário Nacional (DEPEN), do Ministério da Justiça.

${ }^{151}$ Levantamento nacional de informações penitenciárias: INFOPEN Atualização - Junho de 2016/organização, Thandara Santos; colaboração, Marlene Inês da Rosa... [et al.]. - Brasília: Ministério da Justiça e Segurança Pública. Departamento Penitenciário nacional, 2017. Informações complementares estão no site do Ministério da Justiça. Disponível em: <http://www.justiça.gov.br> Acesso em: 09 dez. 2017.

152 Informações colhidas junto ao Conselho Nacional de Justiça. Disponível em: <http://www.politize.com.br/quanto-custa-preso-no-brasil>. Acesso em: 21 nov. 2017.
} 
cerca de seis milhões de moradias ${ }^{153}$. É paradoxal que o sistema criado para dar efetividade à sentença penal condenatória ou, no caso de presos provisórios, mantê-los afastados provisoriamente da sociedade como medida cautelar de prevenção ao cometimento de novos delitos, enfim, para realizar a justiça, seja instrumento da prática da injustiça, pelo custo exorbitante de sua execução. Evidente que todo crime gera a obrigação de reparação do dano. Sob a ótica da Análise Econômica do Direito, é equação irracional, de complexa operação e duvidosa solução, sem garantia de que o encarceramento do autor do crime o obriga a efetuar tal reparação, entendimento adequado à teoria do custo social de Coase (1988). Roxin (1974) afirma que a pena privativa de liberdade de curta duração, em vez de prevenir delitos, na verdade os promove.

\section{PRINCÍPIO DA EFICIÊNCIA E ANÁLISE ECONÔMICA DO DIREITO}

O princípio da eficiência foi incluído no ordenamento jurídico brasileiro pela Emenda Constitucional $n^{\circ}$ 19/98, integrando o arcabouço de princípios da Administração Pública ${ }^{154}$, embora o art. 74 da Constituição Federal já tratasse da eficiência da gestão orçamentária, portanto sem surpresa para a doutrina brasileira: Figueiredo (2003); Mello (2005); Gasparini (2005). Parece evidente que o objetivo da alteração constitucional foi aprimorar a eficiência administrativa e, sob a perspectiva econômica, promover o desenvolvimento nacional na forma do art. $3^{\circ}$, II, da $\mathrm{CF}^{155}$.

Em conformidade com as lições de Gabardo (2002), entende-se eficiência sob três aspectos: a) eficiência econômica stricto sensu (relação entre custos e valor dos resultados); b) eficiência econômica consignativa (distribuição ótima dos recursos disponíveis); c) eficiência econômica produtiva (maior rendimento na utilização dos recursos ou minimização dos custos). Em contraponto ao segundo aspecto, Justen Filho (2005) sustenta que eficiência administrativa não pode ser entendida como eficiência econômica, pois na empresa privada a autonomia autoriza organizar os fatores da produção segundo as finalidades buscadas egoisticamente pelo empresário - o que autoriza, inclusive, privilegiar a busca do lucro.

\footnotetext{
${ }^{153}$ Estima-se que a construção de um presídio de cerca de 500 vagas não custa menos de 20 milhões de reais, enquanto a construção de um presídio federal não custa menos de 40 milhões de reais.

154 O art. 37 da Constituição Federal de 1988 estabelece ainda os princípios da legalidade, impessoalidade, moralidade e publicidade.

155 Art. $3^{\circ}$. Constituem objetivos fundamentais da República Federativa do Brasil: I (...). II - garantir o desenvolvimento nacional.
} 
Sobre o princípio constitucional da eficiência na Administração Pública, Daniel Serra Azul Guimarães lembra que quem atribui caráter estritamente econômico ao princípio da eficiência lastreia-se na noção de maximização da riqueza, considerada como a soma dos valores de todas as coisas materiais e imateriais ${ }^{156}$. De forma semelhante, Meirelles (2003) sustenta que o princípio da eficiência deve ser entendido como dever da Administração Pública, definindo-o como o que se impõe a todo agente público de realizar suas atribuições com presteza, perfeição e rendimento funcional, concebendo-o como o mais moderno princípio da função administrativa, que já não se contenta em ser desempenhado apenas com legalidade, exigindo resultados positivos para o serviço público e satisfatório atendimento das necessidades da comunidade. Para Di Pietro (2018), o princípio da eficiência apresenta dois aspectos: pode ser considerado em relação ao modo de atuação do agente público, do qual se espera o melhor desempenho possível de suas atribuições, para lograr os melhores resultados; e, quanto ao modo de organizar, estruturar, disciplinar a Administração Pública, também com o mesmo objetivo de alcançar os melhores resultados na prestação do serviço público.

Outro traço a ser observado é a base conceitual de eficiência e eficácia para avaliar o desempenho das organizações e de seus administradores, conforme Maximiliano (2000). Para compreender os critérios, é preciso conhecer o significado dos dois termos: enquanto a eficácia diz respeito à escolha dos objetivos e seu atingimento pelos resultados, a eficiência se refere à forma de como os recursos são utilizados para atingir os resultados. Em suma: eficiência está ligada às etapas produtivas e como fazer certo as coisas, ao passo que eficácia está ligada aos resultados e fazer as coisas certas.

Na análise econômica, segundo Campos (2018), a preocupação se volta à medida da eficiência, a qual representa a comparação entre o que foi produzido e o que poderia ter sido produzido com a utilização dos mesmos recursos. A mensuração da eficiência dos agentes econômicos é realizada (i) porque representa um indicador de êxito e (ii) para que se explorem as hipóteses dos diferenciais de eficiência de uma unidade produtiva para outra, conforme Lovell (1992).

Interessa mais compreender como a eficiência é tratada na Análise Econômica do Direito, a partir da segunda metade do século XX, defendendo sua utilização como complemento das justificações doutrinárias para conseguir maior precisão na tomada de decisões, como anota Alvarez (2006). No âmbito da Análise Econômica do Direito, merece

\footnotetext{
${ }^{156}$ Princípio constitucional da eficiência na Administração Pública. Daniel Serra Azul Guimarães. Disponível em: <https://tede2.pucsp.br/bitstream/handle/7660/1/Daniel\%20Serra\%20Azul\%20Guimaraes.pdf $>$ Acesso em: 27 abr. 2018.
} 
destaque a suposta dicotomia entre justiça e eficiência. Para Godoy (2005), a dicotomia entre esses valores é falsa, pois para a decisão ser considerada justa é necessário que a eficiência seja considerada. E a noção de maximização da riqueza, desenvolvida por Posner (1972), seria o critério adequado para que o jurista aplique o Direito de forma eficiente e, portanto, justa.

\section{MEDIDAS DE DESENCARCERAMENTO E CUSTO NOS PRESÍDIOS PÚBLICOS E TERCEIRIZADOS}

Com frequência surgem propostas para reduzir os custos do encarceramento, chamadas de "medidas de desencarceramento ${ }^{157 ",}$, tais como monitoramento eletrônico e descriminalização do uso de drogas. Convém salientar a preocupação do Poder Legislativo com os aspectos econômicos do encarceramento. Destaca-se o Projeto de Lei do Senado $\mathrm{n}^{\circ}$ 580 de 2015, do senador Waldemir Moka (PMDB/MS), que altera a Lei de Execução Penal para estabelecer a obrigação do preso de ressarcir o Estado das despesas com sua manutenção no sistema prisional, mediante recursos próprios ou trabalho.

Concebida como instrumento valioso de política criminal, a monitoração eletrônica de pessoas foi introduzida no sistema processual penal brasileiro com caráter utilitarista: alternativa menos agressiva e custosa ao problema da superlotação dos presídios. Prevista inicialmente na Lei $n^{0}$ 12.258/2010, que alterou a Lei de Execução Penal, o monitoramento eletrônico era aplicado em duas situações: a) saída temporária ao preso que estiver em cumprimento de pena em regime semiaberto (art. 146-B, inciso II); b) quando a pena estiver sendo cumprida em prisão domiciliar (art. 146-B, IV). Com a entrada em vigor da Lei $\mathrm{n}^{\circ}$ 12.403/2011, que alterou o Código de Processo Penal, a monitoração eletrônica passou a ser admitida como medida cautelar diversa da prisão (art. 319, inciso IX), tentativa desesperada para reduzir o alto índice de presos provisórios, que representam 34\% do total de presos no Brasil $^{158}$.

Há de se questionar se o custo com a construção, a reforma, a manutenção e a administração de prédios públicos, deve ser somente do Poder Público, ou se seria mais

\footnotetext{
${ }^{157}$ Essas medidas diferem das medidas despenalizadoras, que afastam a punibilidade do acusado nos termos da Lei n $^{\circ}$ 9.099/1995, como a composição civil (reparação de dano e consequente extinção da punibilidade); a transação penal; a suspensão condicional do processo e a exigência de representação para a lesão leve e culposa. ${ }^{158}$ De acordo com informações do Ministério da Justiça, são 24.203 pessoas monitoradas hoje no Brasil (88\% homens e 12\%mulheres), atingindo 19 unidades da Federação, cujo preço dos serviços varia de R 167,00 a $\mathrm{R} \$ 660,00$.
} 
eficiente sua composição com a iniciativa privada, no regime de parceria público-privada ${ }^{159}$, terceirização ou privatização. Criou-se a ideia de que a administração terceirizada é mais eficiente, porém mais cara, fato comprovado por qualquer levantamento sobre custos do encarceramento $^{160}$. Considerando que dos quase 3 mil estabelecimentos penais apenas $1 \%$ (cerca de 30 estabelecimentos) tem participação da iniciativa privada, não há como atribuir a esse tipo de gestão a responsabilidade preponderante pelo custo exorbitante do encarceramento no Brasil.

Isabela dos Santos lembra que os direitos são caros e todos pressupõem o financiamento por parte dos cidadãos, a partir do recolhimento de tributos, o que significa dizer que todos os direitos dependem de gastos públicos para sua proteção e são os gastos públicos que determinam a extensão e o alcance da proteção de determinada gama de direitos. Por essa razão, é relevante a cooperação social, bem como a compreensão por parte do Estado em relação às escolhas da sociedade como elemento orientador para alocar os recursos necessários à proteção aos direitos ${ }^{161}$.

A afirmação da autora revisita antiga discussão de que um preso tem custo maior para o governo brasileiro que um estudante de ensino superior. Na linha da reflexão citada, todos os direitos têm um custo, de modo que não poderia ser diferente com o direito de punir do Estado, pois também ele vai exigir emprego de recursos públicos para sua salvaguarda ${ }^{162}$.

Embora seja concebido pela sociedade como mal necessário, o encarceramento pode causar desequilíbrio fiscal e comprometer o atendimento das necessidades prementes da população. De fato, a responsabilidade fiscal prevista no art. 165 da Constituição Federal implica o controle de gastos públicos, e o alto custo do encarceramento é ameaça às contas públicas e viola o princípio da eficiência da Administração Pública.

Conforme percepção do Ministério Público do Estado do Amazonas, ao propor seis ações civis públicas autônomas, com foco exclusivo na defesa dos direitos dos presos, após massacres ocorridos nos presídios do Estado em janeiro de 2017, o valor mínimo anual

\footnotetext{
${ }^{159}$ No Brasil, o Complexo Prisional de Ribeirão das Neves é administrado por meio de PPP, no município de mesmo nome, no estado de Minas Gerais, o qual iniciou suas operações em janeiro de 2013. O consórcio de empresas recebe do governo estadual $\mathrm{R} \$ 2.700,00$ por preso por mês e tem a concessão do presídio por 27 anos, prorrogáveis por 35. SACHETTA, Paula. "Quanto mais presos, maior o lucro". Disponível em: <http://apublica.org/2014/05/quanto-mais-presos-maior-o-lucro/>. Acesso em: 4 dez. 2017.

160 O Ministério da Justiça estima que seriam gastos mais de 30 bilhões de reais ao ano para manter todos os presos do país encarcerados em estabelecimentos terceirizados ou em regime de Parceria Público-Privada (PPP).

161 Artigo publicado com o título "O custo dos direitos: o direito de punir estatal e os direitos individuais dos presos". Disponível em <http://ambito-juridico.com.br>. Acesso em: 28 nov. 2017.

162 É importante ressaltar que a comparação pura e simples entre o custo do preso e o custo do aluno é imprecisa porque desconsidera aspectos relevantes da formação dos dois tipos de custos. Com efeito, o compromisso estatal de garantir o exercício dos direitos fundamentais do aluno e do preso não pode ficar à mercê de análises individualistas.
} 
previsto para que o Estado do Amazonas gaste com empresas terceirizadas que administram os estabelecimentos penais foi de $\mathrm{R} \$ 201.574 .674,96$, com a possibilidade de atualização monetária do valor, aditivos por excedentes de presos e a draconiana cláusula de imputar ao Estado os custos de eventual acordo coletivo celebrado entre contratadas e funcionários, sem participação do Estado do Amazonas nas negociações ${ }^{163}$.

Nesse particular, o princípio da eficiência, o qual, conforme doutrina de Mendes (2009), Inocêncio Coelho e Paulo Gustavo Branco, consubstancia a exigência de que os gestores da coisa pública não economizem esforços no desempenho de seus encargos de modo a otimizar o emprego, foi flagrantemente violado.

\section{CONSIDERAÇÕES FINAIS}

Há um longo caminho a trilhar para que o custo do encarceramento se aproxime da realidade econômica do país, porém, só será possível com atitudes corajosas e transparentes dos órgãos dos governos, apuração e divulgação dos critérios de formação dos custos em seus detalhes, discriminadamente, em respeito à Lei da Transparência (Lei Complementar $n^{\circ} 131$, de 27 de maio de 2009) e à Lei de Acesso à Informação (Lei n ${ }^{\circ} 12.527$, de 18 de novembro de 2011). A sociedade deveria conhecer o que e a quem paga para ter política de encarceramento condizente com seu direito fundamental à segurança. Se os dados forem fornecidos honestamente à população, esta passará a encarar com respeito a atividade governamental.

Costuma-se afirmar que o encarceramento é atividade de custo elevado somente no Brasil. Na verdade, o sistema carcerário é especialmente caro nos países subdesenvolvidos ou em desenvolvimento, onde a população carcerária é elevada em razão da sanha do aprisionamento, que faz parte da cultura dos órgãos de repressão desses países, com afetação direta na economia. Parece restar claro que a questão do encarceramento integra o universo da política criminal e penitenciária com reflexos diretos na política econômica de qualquer país desenvolvido ou em desenvolvimento, porque se apodera de recursos carimbados para investimentos sociais.

\footnotetext{
163 Verifica-se que o valor efetivamente pago às terceirizadas pelos agentes de socialização/disciplina chega à quantia de R \$ 3.762,95, enquanto o agente penitenciário de início de carreira da Administração do Estado do Amazonas, objeto da Lei Estadual $\mathrm{n}^{\mathrm{o}} 3.510 / 2010$, possui o vencimento de $\mathrm{R} \$ 1.543,08$, ou seja, menos da metade dos agentes de socialização. Vale frisar que o custo mensal do preso nas unidades terceirizadas no Estado do Amazonas chega a R \$ 4.700,00, portanto três vezes maior que o salário do agente penitenciário do Estado.
} 
Para pôr em relevo os objetivos propostos nesta reflexão, infere-se que, a partir da perspectiva da Análise Econômica do Direito, os diagnósticos sobre o custo do encarceramento, em sua dimensão jurídica, sinalizam para o estabelecimento de modelo unificado de cálculo, em que o princípio federativo constitua a base do que deve ser despendido na gestão do sistema prisional e o fundamento central das políticas públicas no setor. Acredita-se, portanto, que a aplicação de métodos econômicos na apuração do custo do sistema prisional visa garantir a eficiência no cumprimento da pena e a segurança da sociedade por meio da racionalização dos gastos públicos na privação da liberdade, provisória ou definitiva, considerando o estreitamento crescente das relações entre Direito e Economia, fronteira de certa forma inexplorada na área criminal.

A análise apresentada, sem pretensão de esgotar o assunto, evidencia que o número de pessoas encarceradas no Brasil nos últimos dez anos retrata, com fidelidade, a política criminal e penitenciária escolhida pelo Executivo, legitimada pelo Legislativo e referendada pelo Judiciário, consolidando um dos mais rígidos sistemas repressivos da história contemporânea brasileira, cuja severidade gera custos exorbitantes no encarceramento no país, com repercussão direta na economia e nos programas sociais dos governos.

\section{REFERÊNCIAS}

ALVAREZ, Alejandro Bugallo. Análise Econômica do Direito: contribuições e desmistificações. Direito, Estado e Sociedade. Rio de Janeiro: PUC/RJ, v. 9, n. 29, p. 49-68, $\mathrm{jul} / \mathrm{dez} 2006$.

CAMPOS, Eduardo Luiz Cavalcanti. O princípio da eficiência no processo civil brasileiro. Rio de Janeiro: Forense, 2018.

COASE, Ronald H. The firm, the market and the law. Chicago: University of Chicago Press, 1988.

DI PIETRO, Maria Sylvia Zanella. Direito administrativo brasileiro. Direito administrativo. Rio de Janeiro: Forense, 2018.

DI PIETRO, Maria Sylvia Zanella. Parcerias na administração pública. São Paulo: Atlas, 2012. 
DIAS, Jefferson Aparecido. Princípio da eficiência e moralidade administrativa. Curitiba: Juruá, 2004.

DUBOIS, Alexy; KULPA, Luciana; SOUZA, Luiz Eurico de. Gestão de custos e formação de preços: conceitos, modelos e instrumentos - abordagem do capital de giro e da margem de competividade. São Paulo: Atlas, 2009.

DUTRA, René Gomes. Custos: uma abordagem prática. São Paulo: Atlas, 2010.

FAJNZYLBER, P. Determinantes econômicos da criminalidade: notas para uma discussão. Fórum de debates. Criminalidade, violência e segurança pública no Brasil: uma discussão sobre as bases de dados e questões metodológicas. V Encontro: Causas, determinantes, custos e consequências da violência e criminalidade. IPEA, CESeC, UCAM, 2000.

FERREIRA, Cristiana Sanchez Gomes. Análise econômica do divórcio: contributos da Economia ao Direito de Família. Porto Alegre: Livraria do Advogado, 2015.

FIESP, Mercados ilícitos transnacionais em São Paulo: a economia criminal transnacional. São Paulo: FIESP, 2017.

FIGUEIREDO, Lúcia Valle. Curso de Direito Administrativo. São Paulo: Malheiros, 2003.

FRIEDMAN, David D. Law's order - what economics has to do with law and why it matters. Princeton, Princeton University Press, 2000.

GABARDO, Emerson. Princípio constitucional da eficiência administrativa. São Paulo. Dialética, 2002, p. 30.

GASPARINI, Diógenes. Direito administrativo. São Paulo: Saraiva, 2005.

GODOY, Arnaldo Sampaio de Moraes. Direito e economia: introdução ao movimento law and economics. Revista Jurídica, Brasília, v. 7, n. 73, p. 1-10, junho/julho, 2005.

HOLMES, Stephen; SUNSTEIN, Cass R. The cost of rights: why liberty depends on taxes. New York and London: W. M. Norton, 1999.

JUSTEN FILHO, Marçal. Curso de direito administrativo. São Paulo: Saraiva, 2005. 
LOVELL, Knox. Production frontiers and productive efficiency. LOVELL; SCHMIDT (Orgs.). The measurement of productive efficiency: techniques and applications. Oxford University Press, forthcoming, p. 3-21, 1992.

MACKAAY, Ejan; ROUSSEAU, Stéphane. Análise Econômica do Direito. São Paulo: Atlas, 2015.

MAXIMIANO, Antonio Cezar Amaru. Introdução à Administração. São Paulo: Atlas, 2000, p. 115.

MEIRELLES, Hely Lopes. Direito administrativo brasileiro. São Paulo: Malheiros, 2003.

MELLO, Celso Antônio. Curso de Direito Administrativo. São Paulo: Malheiros, 2005.

MENDES, Gilmar Ferreira; COELHO, Inocêncio Mártires; BRANCO, Paulo Gustavo Gonet. Curso de Direito Constitucional. São Paulo: Saraiva; Brasília: IDP, 2009.

NOGUEIRA, José Marcelo; OLIVEIRA, Kátia Michele de; OLIVEIRA, Leonel Gois Lima. Administração da produção na justiça: estudo exploratório da eficiência dos tribunais de justiça estaduais usando análise envoltória de dados (DEA). Anais do SIMPOI 2011. São Paulo: FGV, 2011, p. $7 . \quad$ Disponível em: $<$ http://www.simpoi.fgvsp.br/arquivo/2011/artigos/E2011_T00123_PCN72725.pdf>. Acesso em: 30 abr. 2018.

OLIVEIRA, Ana Francisca; ROSA, Eurycibíades Barra; SIQUEIRA, Márcio. Medindo o desempenho das pequenas indústrias de malhas: um estudo de caso. Economia e Gestão. Belo Horizonte, v. 3, n. 6, p. 109-127, dez. 2003, p. 114.

POSNER, Richard A. Economic Analysis of Law. Boston and Toronto: Little, Brown and Company, 1986.

ROXIN, Claus. A culpabilidade como critério limitativo da pena. Revista de Direito Penal, p. 11-17, Rio de Janeiro, 1974.

SACHETTA, Paula. "Quanto mais presos, maior o lucro". Disponível em <http://apublica.org/2014/05/quanto-mais-presos-maior-o-lucro/>. Acesso em 4 dez. 2017.

SCHMIDTZ, David. Os elementos da justiça. São Paulo: WMF Martins Fontes, 2009. 
SERRA, Marco Alexandre de Souza. Economia política da pena. Rio de Janeiro: Revan, 2009.

SPECTOR, Horacio. Justicia y bienestar. Desde una perspectiva de derecho comparado. Doxa, n. 26, 2003.

\title{
THE COST OF IMPRISONMENT IN BRAZIL FROM THE POINT OF VIEW OF THE ECONOMIC ANALYSIS OF LAW
}

\begin{abstract}
This article presents a survey of the cost of incarceration in Brazil under the Economic Law Analysis. The choice of the topic is justified because it is understood that this is a disregarded issue in the Brazilian criminal and penitentiary world and, to a certain extent, little explored in the academic world and treated in a wrong and exaggerated way in the mass media. The objective of the research is to show that the economic analysis of law is a fundamental instrument for determining the cost of incarceration in its different aspects. It was found that the calculation of the cost of deprivation of liberty in Brazil incurs the omission of relevant aspects that compromise the veracity of the information invariably used in public policy proposals in the area of security. To demonstrate this discrepancy, data collected from a variety of sources are compared, with emphasis on information collected from official institutions and critical analysis of justice through incarceration.
\end{abstract}

Keywords: Incarceration. Cost. Economic analysis of Law. Efficiency. 